\title{
Aortic root complications in Marfan's syndrome: identification of a lower risk group
}

Malcolm E Legget, Trisha A Unger, Corrine K O'Sullivan, Todd R Zwink, Robin L Bennett, Peter H Byers, Catherine M Otto optimising echocardiographic monitoring and risk stratification of patients with Marfan's syndrome.

(Heart 1996;75:389-395)

Keywords: Marfan's syndrome; aortic root complications; echocardiography; prognosis

The Marfan syndrome is an autosomal dominant inherited disorder of connective tissue with pleiotropic and variable manifestations in multiple organ systems. ${ }^{1}$ Aortic root pathology, including aneurysmal dilatation and dissection, is the major cause of morbidity and mortality in these patients. ${ }^{2}$ Serial echocardiographic aortic root measurements are an important means of surveillance, given the improved long-term prognosis after aortic root replacement. ${ }^{3}$ It was suggested in a recent study that generalized aortic root dilatation was a predictor of subsequent aortic complications in patients with Marfan's syndrome. ${ }^{4}$ However, that study ${ }^{4}$ and two other recent studies $^{56}$ showed wide variability in the rates of change in aortic dimensions in cohorts of patients with Marfan's syndrome. For optimal monitoring and risk stratification, more data are needed to determine which clinical and echocardiographic variables predict outcome in patients with Marfan's syndrome.

The aim of this study was to identify clinical and echocardiographic predictors of outcome in a large cohort of patients with Marfan's syndrome. We hypothesised that aortic complications were more likely in those with (a) greater initial aortic root dimensions for age and body size and (b) more rapid progression of aortic dilatation. $(0.2), P<0.0001)$. In the 62 patients with serial echocardiographic follow up, the rate of aortic root dilatation was more rapid in those with events (15 (17) $v 0$ (3)\%/year, $\mathbf{P}<0.0001)$. Utilising a Cox proportional hazards model, the groups with an initial aortic ratio $\geqslant 1.3$ or an annual change in aortic ratio $\geqslant 5 \%$ had a relative risk of an aortic complication of $2 \cdot 7$ and $4 \cdot 1$, respectively (95\% confidence limits 1.5 to $4 \cdot 8$ and $1 \cdot 8$ to $9 \cdot 3)$. Only one of 31 patients with an initial aortic ratio of $<1.3$ and a rate of change of $<5 \%$ had an event (five year event free survival 97\%). Conclusions-A low risk subgroup of patients with Marfan's syndrome can be identified as those with an aortic ratio $<1.3$ and an annual change in aortic ratio of $<5 \%$. These findings are helpful in

\section{Patients and methods}

PATIENTS

The records of 100 patients with definite Marfan's syndrome referred to the University of Washington Medical Center or Children's Hospital and Medical Center genetics clinics between 1977 and 1994 were reviewed for possible inclusion in this study. Follow up information was available or could be obtained in 89 patients (from 68 families) who comprise the study group. Most individuals with Marfan's syndrome in our geographical area are referred to these clinics, even when the primary physician is not university affiliated. In addition, the local Marfan society was contacted to ensure that all known individuals 
with Marfan's syndrome were included. The diagnosis of the Marfan's syndrome was made according to the criteria of Pyeritz and McKusick $^{1}$ and only patients satisfying strict diagnostic criteria were included. The mean (range) period of follow up from the initial diagnosis of Marfan's syndrome was 4 $(<1-16)$ years. The protocol for this study was approved by the University of Washington and Children's Hospital Institutional Review Boards and informed consent was obtained.

\section{FOLLOW UP}

Clinical, echocardiographic, and outcome data available were collected by reviewing genetics clinic and hospital charts and telephone interview. A standardized data collection form was utilised, which included demographic details, vital statistics, whether aortic root surgery had been performed, and a detailed account of the patient's usage of $\beta$ blocking medication. The defined outcomes were (a) the end point of death or root replacement for ascending dissection or (b) ascending aortic events defined as those with an end point plus those undergoing surgery for ascending aortic aneurysm. The decision to perform aortic surgery was made by each patient's physician based on clinical, as well as echocardiographic, data. The aortic root ratio or the change in root ratio was not used in clinical decision making. In addition to aortic root dilatation, the indications for aneurysm surgery included increasing aortic regurgitation or new cardiac symptoms, or both, in seven $(78 \%)$ of nine of these patients.

There were four patients with descending aortic dissections of whom only one was considered to have reached an end point (one also had aortic root replacement for ascending aneurysm). The other three patients with isolated descending aortic dissections were censored at the time of the event but were not considered an end point, as the study goal was to predict ascending aortic complications. One patient died after descending aortic dissection. Inclusion of this death as an end point does not change the statistical significance of the results. Patients were also grouped into those receiving $\beta$ blocking drugs for $>12$ months and those who never received them or took them for $<12$ months.

\section{ECHOCARDIOGRAPHIC FOLLOW UP}

Echocardiographic data were available in 80 $(90 \%)$ of 89 patients. Serial echocardiographic studies were available in $62(70 \%)$ of 89 patients with a median (range) of serial studies per patient of $4.6(2-13)$. Patients who had not had an echocardiogram within the previous year underwent a clinical evaluation and echocardiographic examination focusing on aortic dimensions and pathology at the University of Washington Medical Center (n $=18$ ).

Detailed measurements of the aortic root were made in the parasternal long axis view according to the method of Roman et $a l^{7}$ by an investigator unaware of clinical outcome in the 98 echocardiograms in which the original video tape could be obtained. In the other studies ( $n=199$ ) official reports were used. Aortic diameter measurements were made using the leading edge technique at end diastole (defined as the peak of the $R$ wave on the electrocardiogram). Maximal diameter measurements were recorded at the aortic annulus, the sinuses of Valsalva, the sinotubular junction, and proximal ascending aorta $1-2 \mathrm{~cm}$ above the sinotubular junction. All diameters were measured perpendicular to the long axis of the aorta.

The maximum dimension of the sinuses of Valsalva (available in all studies) was used to calculate an aortic ratio. The observed dimension was divided by the predicted dimension based on age and body surface area using the following established regression formulas derived from normal individuals: ${ }^{7}$

$$
\begin{gathered}
\text { Children (age }<18 \text { years): predicted sinus } \\
\text { dimension }(\mathrm{cm})= \\
1.02+\left(0.98 \times \mathrm{BSA}\left(\mathrm{m}^{2}\right)\right) \\
\text { Adults (age } 18-40 \text { years): predicted sinus } \\
\text { dimension }(\mathrm{cm})= \\
0.97+\left(1.12 \times \mathrm{BSA}\left(\mathrm{m}^{2}\right)\right) \\
\text { Adults }(>40 \text { years): predicted sinus } \\
\text { dimension }(\mathrm{cm})= \\
1.92+\left(0.74 \times \mathrm{BSA}\left(\mathrm{m}^{2}\right)\right)
\end{gathered}
$$

where BSA is body surface area.

This allowed for comparisons of aortic root dimensions among all patients regardless of age and body size. For example, an aortic sinus ratio of 1.3 indicates a $30 \%$ enlargement of the aortic root above the mean for that patient's age and body surface area. The rate of aortic root dilatation normalized for age and body size was calculated by determining the change in aortic ratio between the final and initial echocardiograms and dividing by the interval between them in years. Mitral valve prolapse and aortic regurgitation were evaluated using established cross sectional echocardiographic and colour Doppler diagnostic criteria. $^{8-10}$

\section{STATISTICAL ANALYSIS}

Demographic and echocardiographic variables in patients with versus those without an aortic event or end point were compared using $\chi^{2}$ analysis for dichotomous variables and the unpaired Student's $t$ test for continuous variables. Data are presented as mean (one SD). Kaplan-Meier life table analysis was performed for overall and event free survival. The log rank test was used to examine differences between survival curves in those who had taken $\beta$ blocking medication for $>$ one year or $\leqslant$ one year. The time period of one year for $\beta$ blocker treatment was chosen because some patients took $\beta$ blockers for only a few days and then discontinued them because of side effects. The results are not affected by using a different cut off point (e.g. one month) for duration of $\beta$ blocker treatment.

Cox proportional hazards regression was performed to examine baseline variables that were found on univariate analysis to be associated with a poor outcome. For the Cox regression model, an aortic ratio $\geqslant$ or $<1 \cdot 3$, and an 
Table 1 Demographic and echocardiographic features of 89 patients with Marfan syndrome

\begin{tabular}{ll}
\hline Feature & \\
\hline Mean (SD) (range) age at entry (years) & 21 (13) (1-54) \\
Age < 18 years at enrolment (\%) & 46 \\
Sex (M/F) & $49 / 40$ \\
Family history (\%) & 56 \\
Organ system (\%) & 91 \\
Cardiovascular & 94 \\
Musculoskeletal & 83 \\
Ocular & \\
Clinical findings (\%) & 63 \\
Mitral prolapse & 38 \\
Spinal deformity & 54 \\
Hyperextensibility & 44 \\
Ectopia lentis & 36 \\
$\beta$ blocker treatment (\%) & 64 \\
₹1 year & \\
<1 year & 71 \\
Aortic regurgitation (\%) & 11 \\
None & 3 \\
Mild to moderate & 15 \\
Severe & \\
Unknown & 59 \\
Mitral regurgitation (\%) & 25 \\
None & 1 \\
Mild to moderate & 15 \\
Severe & \\
Unknown & \\
\hline
\end{tabular}

annual rate of change of aortic ratio $\geqslant$ or $<5 \%$ were used as break points to compare outcome. These break points were used because 1.3 was the mean ratio for the entire cohort, and an annual rate of change of $5 \%$ represents approximately a $2 \mathrm{~mm}$ increase in aortic root dimension in adults, which would be detectable by cross sectional echocardiography. Age was included in the model to allow for any possible confounding effect of age on aortic dilatation. Follow up time for each of these analyses was calculated as the time from the first genetics clinic visit (the time when Marfan's syndrome was definitely diagnosed) to an end point or until the end of the study. Statistical package for the social sciences (SPSS for Windows, version 6.0) with default settings was used for all statistical analyses.

\section{Results}

DEMOGRAPHIC FEATURES

Table 1 lists the demographic and clinical characteristics of the 89 patients with Marfan's syndrome. There were 49 males and 40 females with an age range from 1 to 54 (median 21) years. Cardiovascular and musculoskeletal features were present in nearly all patients. Ocular findings were present in $83 \%$ of patients and included iridodonesis, lens dislocation, or a history of retinal detachment. A positive family history of Marfan's syndrome was present in $56 \%$ of patients, while $44 \%$ represented new mutations. Although $45 \%$ (37 of 83 patients) of patients had taken $\beta$ blocking medication at some time in the follow up period, only $36 \%$ ( 30 of 83 ) took $\beta$ blockers continuously for greater than 12 months. $\beta$ blocker history was unknown in six patients.

OVERALL SURVIVAL AND EVENT-FREE SURVIVAL Figure 1 shows Kaplan-Meier life table analysis for overall survival, freedom from aortic dissection, and event free actuarial survival. Actuarial survival at two and five years for the whole group was $96 \%$ and $92 \%$, and freedom from all events was $85 \%$ and $76 \%$, respec-

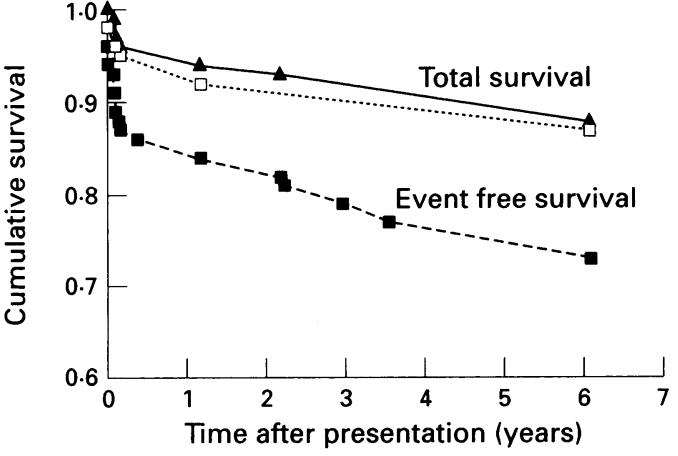

No at follow up

$$
\begin{array}{llllll}
62 & 50 & 41 & 31 & 25 & 18
\end{array}
$$

Figure 1 Kaplan-Meier total survival (-), survival without dissection of the ascending aorta (...) and event free survival (- - -) in 89 patients with Marfan's syndrome.

tively. The Kaplan-Meier mean total survival was 14.6 (95\% confidence intervals (CI) 13.4 to $15 \cdot 8$ ) years and mean event free survival was $12 \cdot 0(95 \% \mathrm{CI}) 10.3$ to 13.6$)$ years from presentation.

At follow up 71 of 89 patients were alive with no ascending aortic complications. The 18 end points included five deaths due to ascending dissection, four patients who survived emergency aortic root replacement for ascending aortic dissection, and nine patients who underwent a composite graft replacement for ascending aortic aneurysm (table 2). Surgery or death occurred < one year after the initial diagnosis in 11 of 18 patients with an end point, thus, follow up is shorter in those with an event. The mean (range) age at death was 30 (17-54) years and for all aortic complications was also $30(10-54)$ years.

\section{CLINICAL CHARACTERISTICS OF THOSE WITH} AND THOSE WITHOUT AORTIC COMPLICATIONS There were no significant differences between those with and those without aortic complications other than an older age and shorter follow up period in those with aortic complications (table 3). Fifty three per cent of those having an aortic complication had a first degree relative with an aortic complication or died due to aortic dissection. Results are similar if only those with a definite end point (death or dissection) are compared with the remainder of the study group.

\section{ECHOCARDIOGRAPHIC FOLLOW UP}

In the 80 patients with one or more echocardiograms, the initial aortic sinus dimension in those with an aortic complication averaged 47 (range 31-83) $\mathrm{mm}$ compared with 33 (range 20-50) $\mathrm{mm}$ in those without a complication $(P<0.0001)$. This was reflected in the aortic ratio which averaged 1.6 in those with an event compared with 1.3 in those without $(\mathrm{P}<$ $0.0001)$. The initial aortic ratio was $\geqslant 1.3$ in $77 \%$ of patients with a complication versus $35 \%$ of patients without $\left(\chi^{2}=0 \cdot 01\right)$. Similar changes were seen in the aortic dimensions at 
Table 2 Clinical and echocardiographic features of 18 patients with aortic complications or who died

\begin{tabular}{|c|c|c|c|c|c|c|c|c|}
\hline $\operatorname{Sex}$ & $\begin{array}{l}\text { Age } \\
\text { (years) }\end{array}$ & $\begin{array}{l}\text { Initial sinus } \\
\text { dimension } \\
\text { ratio }\end{array}$ & $\begin{array}{l}\text { Interval } \\
\text { between } \\
\text { echos }\end{array}$ & $\begin{array}{l}\text { Final sinus } \\
\text { dimension } \\
\text { ratio }^{\star}\end{array}$ & $\begin{array}{l}\triangle \text { Aortic } \\
\text { ratio† }\end{array}$ & $\begin{array}{l}\text { Interval } \\
\text { before } \\
\text { complication } \ddagger\end{array}$ & Complication & Outcome \\
\hline $\mathbf{M}$ & 22 & & & $83 / 2 \cdot 6$ & & 1 day & $\begin{array}{l}\text { Death due to ascend- } \\
\text { ing dissection }\end{array}$ & $\begin{array}{l}\text { Death } 2 \text { months after aortic root and } \\
\text { valve replacement } \\
\text { Recurrent cardiac arrest, poor left } \\
\text { ventricular function }\end{array}$ \\
\hline $\mathrm{F}$ & 36 & & & $42 / 1 \cdot 3$ & & 1 month & $\begin{array}{l}\text { Death due to ascend- } \\
\text { ing dissection }\end{array}$ & Death during emergency aortic surgery \\
\hline $\mathbf{M}$ & 18 & & & $48 / 1 \cdot 8$ & & 2 years & $\begin{array}{l}\text { Death due to ascend- } \\
\text { ing dissection }\end{array}$ & Death during emergency aortic surgery \\
\hline $\mathbf{M}$ & 19 & & & $46 / 1 \cdot 7$ & & 6 years & $\begin{array}{l}\text { Death due to ascend- } \\
\text { ing dissection }\end{array}$ & $\begin{array}{l}\text { Sudden death } \\
\text { Postmortem examination confirmed } \\
\text { ascending dissection }\end{array}$ \\
\hline $\mathrm{F}$ & 26 & & & $38 / 1 \cdot 3$ & & 6 months & $\begin{array}{l}\text { Death due to ascend- } \\
\text { ing dissection }\end{array}$ & $\begin{array}{l}\text { Died } 16 \text { days after emergency aortic } \\
\text { surgery at } 10 \text { weeks postpartum }\end{array}$ \\
\hline F & 31 & $34 / 1 \cdot 2$ & 10 years & $42 / 1 \cdot 4$ & 0.02 & 8 months & Ascending dissection & $\begin{array}{l}\text { Successful composite graft repair } \\
\text { Alive at } 5 \text { years }\end{array}$ \\
\hline $\mathbf{F}$ & 32 & & & $42 / 1 \cdot 5$ & & 1 year & Ascending dissection & $\begin{array}{l}\text { Successful composite graft repair } \\
\text { Alive } 13 \text { years after operation }\end{array}$ \\
\hline $\mathbf{M}$ & 43 & & & Not done & & & Ascending dissection & $\begin{array}{l}\text { Composite graft repair } \\
\text { Subsequent descending dissection } \\
\text { Alive } 8 \text { years after operation }\end{array}$ \\
\hline$M$ & 34 & & & Not done & & & Ascending dissection & $\begin{array}{l}\text { Composite graft repair } \\
\text { Subsequent arch descending dissection } 1 \text { year } \\
\text { after operation and with revision of } \\
\text { ascending graft } \\
\text { Alive } 3 \text { years after second operation }\end{array}$ \\
\hline $\mathbf{M}$ & 24 & $49 / 1 \cdot 4$ & 8 months & $61 / 1 \cdot 7$ & 0.5 & 1 month & Ascending aneurysm & $\begin{array}{l}\text { Composite graft subsequent revision } 7 \text { years } \\
\text { later and descending aortic replacement } \\
12 \text { years later } \\
\text { Alive }\end{array}$ \\
\hline $\mathbf{M}$ & 43 & $34 / 1 \cdot 0$ & 6 years & $51 / 1 \cdot 5$ & 0.09 & 2 months & Ascending aneurysm & $\begin{array}{l}\text { David's procedure (graft and resuspension of } \\
\text { native aortic valve) }\end{array}$ \\
\hline $\mathbf{M}$ & 46 & & & $64 / 1 \cdot 8$ & & 2 months & Ascending aneurysm & $\begin{array}{l}\text { Composite graft } \\
\text { Alive } 8 \text { years after operation }\end{array}$ \\
\hline $\mathbf{M}$ & 19 & $31 / 1 \cdot 3$ & 8 years & $58 / 1 \cdot 8$ & 0.06 & 5 months & Ascending aneurysm & $\begin{array}{l}\text { Composite graft } \\
\text { Subsequent infection and reoperation } 1 \text { year later }\end{array}$ \\
\hline $\mathbf{F}$ & 32 & & & Not done & & 1 day & Ascending aneurysm & $\begin{array}{l}\text { Alive } 5 \text { years after operation redo AVR } \\
16 \text { years after operation }\end{array}$ \\
\hline $\begin{array}{l}\mathrm{F} \\
\mathrm{M} \\
\mathrm{F} \\
\mathrm{M}\end{array}$ & $\begin{array}{l}24 \\
31 \\
38 \\
10\end{array}$ & $\begin{array}{l}38 / 1 \cdot 3 \\
34 / 1 \cdot 0\end{array}$ & $\begin{array}{r}9 \text { years } \\
10 \text { years }\end{array}$ & $\begin{array}{l}70 / 2 \cdot 4 \\
60 / 1 \cdot 8 \\
55 / 1 \cdot 6 \\
57 / 2 \cdot 8\end{array}$ & $\begin{array}{l}0.13 \\
0.08\end{array}$ & $\begin{array}{l}5 \text { days } \\
2 \text { months } \\
13 \text { months } \\
2 \text { days }\end{array}$ & $\begin{array}{l}\text { Ascending aneurysm } \\
\text { Ascending aneurysm } \\
\text { Ascending aneurysm } \\
\text { Ascending aneurysm }\end{array}$ & $\begin{array}{l}\text { Composite graft alive } 9 \text { years after operation } \\
\text { Composite graft lost to follow up after operation } \\
\text { Composite graft alive } 9 \text { years after operation } \\
\text { Alive } 4 \text { years post-composite graft }\end{array}$ \\
\hline
\end{tabular}

* Sinus dimension in millimetres; ratio is dimensionless on final echocardiogram before complication occurred. +Change in aortic ratio between first and last echocardiograms divided by interval in years. Multiply a 100 for $\%$ change/year. $¥$ Time interval between final echocardiographic study and aortic complication.

the sinotubular junction and ascending aortic levels, although the number of measurements was smaller. The mean sinotubular junction dimension on the final echocardiogram in those with versus those without an aortic complication was 41 (10) $v 31$ (5) $\mathrm{mm}(\mathrm{P}=$ $0.001)$. Similarly, the ascending aorta measured $35(11) v 27(7) \mathrm{mm}(\mathrm{P}=0.03)$. Although the average sinus of Valsalva dimension on the most recent echocardiographic study before the aortic complication was 51 (range 38-83) $\mathrm{mm}$, it is noteworthy that four patients (all women) had an aortic root dimension of only between 38 and $46 \mathrm{~mm}$ in the year before aortic dissection. Only one of these women was postpartum (fig 2).

Table 4 compares echocardiographic findings in the 62 patients with serial studies. The mean baseline sinus dimension and aortic ratio were no different in those who developed a complication versus those who remained event free. However, the changes in aortic sinus dimension and aortic ratio/year of follow up were significantly greater in those with a complication than in those without. The annual rate of change in aortic ratio was $\geqslant 5 \%$ in only four $(8 \%)$ of 51 of those without a complication compared with five $(83 \%)$ of six of those with a complication $\left(\chi^{2}=0.001\right)$ (table 4). A more rapid rate of dilatation (i.e. $\geqslant$ $5 \% /$ year) was detected only in patients who were subsequently referred for aortic root replacement for ascending aneurysm. Serial echocardiographic data were available only in one patient with acute ascending dissection

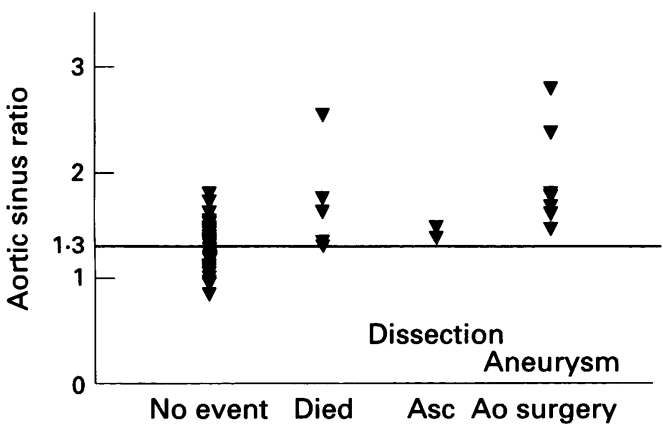

Figure 2 Initial aortic sinus ratio in those with no event, those who died, and those who underwent surgery for ascending aortic (ASC Ao) dissection or aneurysm.

\begin{tabular}{llll}
\hline Feature & $\begin{array}{l}\text { No event } \\
(n=71)\end{array}$ & $\begin{array}{l}\text { Event } \\
(n=18)\end{array}$ & $p$ Value \\
\hline Enrolment age (year) & $19(12)$ & $29(12)$ & $0 \cdot 003$ \\
Age at follow up (year) & $25(13)$ & $35(12)$ & $0 \cdot 007$ \\
Body surface area (m $\left.{ }^{2}\right)$ & $1.5(0 \cdot 5)$ & $1 \cdot 8(0 \cdot 6)$ & $0 \cdot 05$ \\
Sex (M/F)(\%) & $55 / 45$ & $56 / 44$ & NS \\
Follow up (year) & $4 \cdot 7(4 \cdot 5)$ & $1 \cdot 6(2 \cdot 7)$ & $0 \cdot 004$ \\
$\beta$ blocker treatment & 37 & 58 & NS \\
Duration of $\beta$ blocker treatment (months) & $20(43)$ & $40(58)$ & NS \\
Family history (\%) & 57 & 44 & NS \\
Ectopia lentis (\%) & 47 & 32 & NS \\
Spinal deformity (\%) & 36 & 47 & NS \\
Mitral prolapse (\%) & 60 & 74 & NS \\
\hline
\end{tabular}

Values are mean (SD) unless specified otherwise. ${ }^{\star}$ Events defined as death or surgery for ascending aortic dissection or aneurysm. NS, not significant. 
Table 4 Serial echocardiographic findings $(n=62)$

\begin{tabular}{|c|c|c|c|}
\hline & $\begin{array}{l}\text { No event } \\
(n=56)\end{array}$ & $\begin{array}{l}\text { Event } \\
(n=6)\end{array}$ & $p$ Value \\
\hline $\begin{array}{l}\text { Body surface area } \\
\text { Sinus dimension }(\mathrm{mm})(\mathrm{n}=62)\end{array}$ & $1.6(0.5)$ & $1.9(0.3)$ & NS \\
\hline \multicolumn{4}{|l|}{ Sinus dimension $(\mathrm{mm})(\mathrm{n}=62)$} \\
\hline Baseline & $34(8)$ & $37(6)$ & NS \\
\hline Follow up & $38(7)$ & $57(10)$ & $<0.0001$ \\
\hline$\Delta$ sinus & $5(5)$ & $20(9)$ & $<0.0001$ \\
\hline$\Delta$ sinus/year & $0 \cdot 7(1)$ & $5 \pm 6$ & $<0.0001$ \\
\hline \multicolumn{4}{|l|}{ Sinus ratio $(n=57)$} \\
\hline Baseline & $1 \cdot 3(0 \cdot 2)$ & $1 \cdot 2(0 \cdot 2)$ & NS \\
\hline Follow up & $1 \cdot 3(0 \cdot 2)$ & $1.8(0.4)$ & $<0.0001$ \\
\hline$\Delta$ ratio & $0.03(0 \cdot 1)$ & $0.6(0.3)$ & $<0.0001$ \\
\hline$\Delta$ ratio/year & $0.00(0.03)$ & $0 \cdot 15(0 \cdot 17)$ & $<0.0001$ \\
\hline
\end{tabular}

Values are mean (SD). NS, not significant.

Figure 3 Examples of the rate of change in aortic sinus ratio over the follow up period. In these 12 patients with Marfan's syndrome, two underwent surgery for ascending aortic aneurysm and increasing aortic

regurgitation ( $\left.\mathbf{\Delta}-\mathbf{- D}^{--}\right)$ while the remaining 10 had no aortic complications (一).

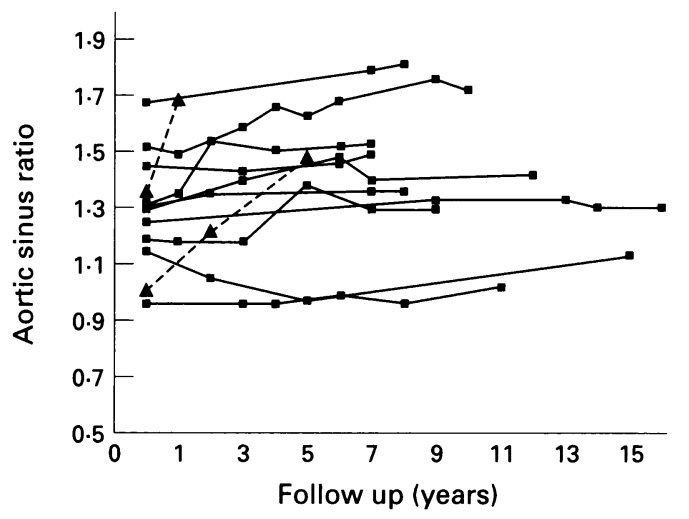

who had an annual increase in aortic ratio (at the sinus) of $2 \% /$ year (table 2 ). It is noteworthy that the rate of change in the aortic root ratio was heterogeneous among the study group (fig 3) with some patients having little change over long follow up intervals.

\section{COX REGRESSION ANALYSIS}

Cox regression analysis was performed to examine the independent predictive value of the initial aortic ratio on outcome. The Cox model included age as a covariate to avoid any potential bias and as seen in fig 4 , the aortic root ratio is not related to age. In patients with at least one echocardiogram $(n=80)$, the relative risk of an aortic complication in those with an aortic ratio of $\geqslant 1.3$ was $2.7(95 \%$ CI 1.5 to $4 \cdot 8, \chi^{2}=0.007$ ) (fig 5) and the risk of death or aortic dissection was 3.6 (95\% CI 1.2 to 10.5 , $\left.\chi^{2}=0.02\right)$. For those patients who had two or more echocardiograms $(n=62)$, the relative risk of aortic complications was $4 \cdot 1$ (95\% CI 1.8 to $\left.9.3, \chi^{2}=0.0005\right)$ in those with an annual change in the aortic ratio $\geqslant 0.05$, however the relative risk for death or dissection alone was not significant because of the small number of end points in this subgroup.

Figure 4 Initial aortic sinus ratio versus age showing that there is no significant relation between these two variables. Patients with no event (○), those who died ( $\square$ ), and those who had ascending aortic surgery for dissection ( $\mathbf{\Delta})$ or aneurysm $(\triangle)$ are indicated.

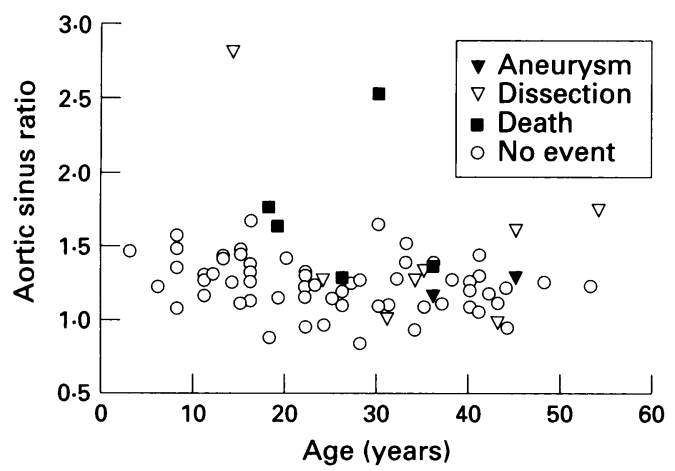

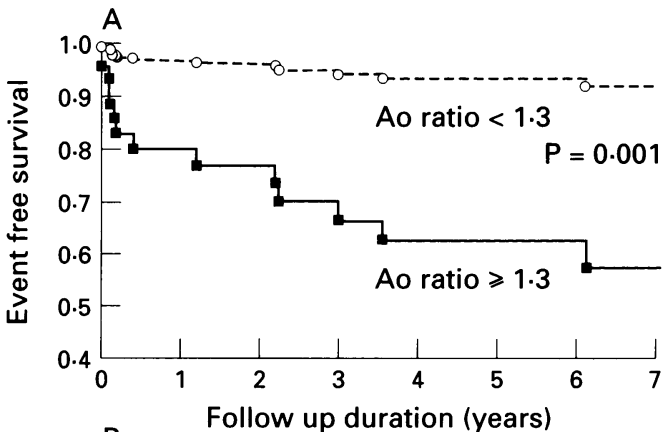

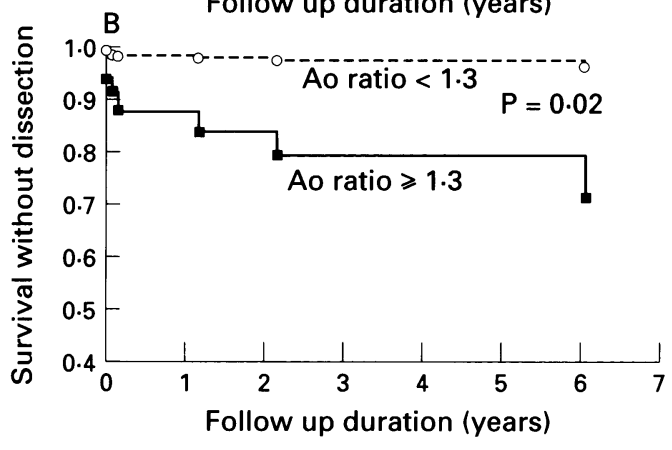

Figure 5 Cox proportional hazards model showing $(A)$ event free survival and $(B)$ survival without ascending aortic dissection in patients with an initial aortic sinus (Ao) ratio of $<1 \cdot 3$ versus those with a ratio of $\geqslant 1 \cdot 3$.

A lower risk group was defined as patients with an initial aortic ratio $<1.3$ and a rate of change of aortic ratio $<5 \% / y e a r$. Only one $(3 \%)$ of 31 of these patients had an aortic complication compared with $14(36 \%)$ of 39 patients who had an initial aortic ratio of $\geqslant 1.3$ or an annual rate of change of $\geqslant 5 \%$. The relative risk of a complication in this low risk subgroup was $0.3\left(95 \%\right.$ CI 0.09 to $0.71, \chi^{2}=$ $0.001)$. The predictive value of these variables in predicting freedom from an event was therefore $97 \%$. Dissection or death occurred in only one $(3 \%)$ of 31 of this low risk subgroup versus six $(15 \%)$ of 39 with an aortic ratio $\geqslant 1.3$ or annual rate of change $\geqslant 5 \%$. Use of this more definitive end point did not reach statistical significance because of the small number of end points.

To examine the effect of patients who presented acutely on the Cox regression model, the eight patients with follow up times < one month were excluded from analysis. Similar results were obtained with a relative risk of a complication of $2 \cdot 8(95 \%$ CI 1.4 to 5.5$)$ for those with an initial aortic ratio of $\geqslant 1.3$ and a relative risk of $5.9(95 \%$ CI 2.0 to $17 \cdot 3)$ for those with a rate of change in aortic ratio of $\geqslant$ $0.05 /$ year.

\section{$\beta$ BLOCKER TREATMENT}

Thirty patients received $\beta$ blockers for $\geqslant$ one year while 53 patients either never received $\beta$ blockers or took them for $<$ one year. Aortic ratios and the change in ratio between initial and final echocardiograms did not differ between these groups. Actuarial freedom from all events was no different in those receiving $\beta$ blockers (69\%, nine events in 28 patients) compared with those not receiving $\beta$ blockers $(85 \%$, eight events in 55 patients) at five years $(P=$ not significant, log rank test). 


\section{Discussion}

ECHOCARDIOGRAPHIC PREDICTORS OF OUTCOME

This study demonstrates that echocardiographic variables are powerful predictors of outcome in patients with Marfan's syndrome. In those in whom serial echocardiographic measurements of aortic dimensions were available, the rate of dilatation of the aortic root was significantly more rapid in those with complications. The mean change in aortic ratio in those suffering a complication was $0 \cdot 15$ /year indicating an average increase of $15 \%$ in aortic dimension/year, after allowing for the effect of increasing age and body size. This contrasts with almost no change in the aortic ratio seen in those not experiencing a complication. Thus, an annual change in the aortic ratio $<5 \%$ indicates that the patient is unlikely to suffer an aortic complication (predictive value $92 \%$ ). In an individual patient with Marfan's syndrome, a consistent pattern of change on serial echocardiography is helpful in distinguishing progressive root dilatation from measurement variability.

Although the number of serial echocardiographic studies in patients with a complication was small because a number of patients had their complication soon after their initial study, our findings remain significant even when these patients are excluded. Thus, the finding of more rapid dilatation underscores the need for more frequent surveillance especially in patients at high risk, either because of a strong family history of aortic complication, or significant aortic dilatation at baseline.

The importance of calculating an aortic ratio also must be emphasised. Aortic dimensions were between 38 and $46 \mathrm{~mm}$ in four patients recorded within one year of ascending dissection. These four patients (all women) had body surface areas between $1 \cdot 70$ and $2 \cdot 27 \mathrm{~m}^{2}$, so that their aortic ratios were between $1 \cdot 3$ and $1 \cdot 4$. As women generally have a smaller body size, the magnitude of aortic dilatation may not be appreciated when only the absolute sinus dimension is considered. The prognostic value of the aortic ratio is further emphasised by the Cox proportional hazards model. Patients with an initial aortic sinus ratio $\geqslant 1 \cdot 3$ had an almost threefold risk of an aortic complication over the follow up period compared with that in those with an aortic ratio $<1 \cdot 3$. In a man with a body surface area of $2.0 \mathrm{~m}^{2}$, an aortic ratio of 1.3 corresponds to an aortic sinus dimension of approximately $42 \mathrm{~mm}$. In a woman with a body surface area of $1.8 \mathrm{~m}^{2}$, a ratio of 1.3 corresponds to an aortic sinus dimension of $39 \mathrm{~mm}$. The current general recommendation for prophylactic aortic root replacement is at an aortic dimension of 55-60 mm, ${ }^{11-15}$ which would correspond to an aortic ratio of $1 \cdot 7-1.9$ in the male and $1 \cdot 8-2 \cdot 0$ in the female examples given here. In our population a substantial number of complications occurred in patients with aortic root dimensions less than that for which prophylactic root replacement is routinely performed (fig 2) as noted in other studies. ${ }^{61617}$ However, no complications occurred in patients with an aortic ratio $<1 \cdot 3$
LONG-TERM OUTCOME IN PATIENTS WITH

MARFAN'S SYNDROME

With current cardiac surgical techniques and improved echocardiographic monitoring, long-term survival in patients with Marfan's syndrome is reasonably good. However, there is a substantial incidence of aortic complications. All deaths in this series were due to aortic dissection, including two patients not previously known to have Marfan's syndrome or aortic root pathology. While the $20 \%$ incidence of aortic complications over a mean follow up period of four years is similar to that in recently published series, ${ }^{3-5}$ the survival of $92 \%$ for the whole cohort at five years seems to be better, probably because all patients underwent a composite graft usually with the classic Bentall's technique $^{18}$ rather than the older technique of an interposition tube graft. There were no early postoperative deaths with elective surgery ( $n=$ 9) for aortic dilatation. With emergency surgery for dissection, four ( $50 \%$ ) of eight patients died intraoperatively or in the early postoperative period. The long-term survival of patients with aortic complications who survived surgery was excellent, with no known deaths a mean of $8 \cdot 1$ years after aortic root replacement. However, four of 13 patients surviving aortic surgery required reoperation, two for further dissection, one because of graft infection, and one because of severe bioprosthetic aortic valve incompetence. These data are in agreement with previous studies showing a five and 10 year actuarial survival after composite graft repair between 71 and $93 \%$ and 54 and $76 \%$, respectively. ${ }^{11-13}$

OTHER PREDICTORS OF OUTCOME

The importance of factors not evaluated in this study cannot be discounted. For example, the high incidence of complications in patients who had first degree relatives with aortic complications emphasises the adverse prognostic importance of a positive family history of aortic dissection. ${ }^{1519}$ In addition, cardiovascular risk may differ within families as well as with some members having milder phenotypes not associated with aortic involvement. ${ }^{20}$

The retrospective nature and relatively small sample size of this study make interpretation of the data pertaining to $\beta$ blocker treatment difficult. Some patients presented acutely with dissection and previously undiagnosed Marfan's syndrome, a bias that favours $\beta$ blockade. Conversely, it is likely that those with more severe disease (e.g. family history, larger aortic dimension, and rapid rate of aortic dilatation) were selected for treatment which would bias against $\beta$ blockade. Overall, no significant differences between the two groups were observed.

\section{Conclusions}

Long-term prognosis in patients with Marfan's syndrome is reasonably good, but a significant number of aortic complications occur, even in patients with only moderately dilated aortic roots. Until a molecular based approach is widely available that will identify patients at high cardiovascular risk, echocardiographic 
variables will remain the most important prognostic indicators. The present study suggests that any patient with an aortic ratio $\geqslant 1.3$ ( $30 \%$ greater than normal) or a change in aortic ratio $>5 \% /$ year should be followed closely as there is a high risk of complications. Patients with aortic ratios of $<1.3$ and a rate of change of $<5 \%$ seem to be at low risk. Prospective validation of these proposed criteria is needed.

We are grateful to the Washington State Marfan Association for their cooperation and to Sharon Kemp for typing this manuscript. MEL was supported by a grant from the National Heart Foundation of New Zealand, and TAU by a grant from the University of Washington Medical Student Research Training Program. This study was supported in part by a grant from the United States Public Health Service (AR 21557).

1 Pyeritz RE. The Marfan syndrome. In: Royce PM, Steinmann B, eds. Connective tissue and its heritable disorders. New York: Wiley, 1992:436-68.

2 Murdoch JL, Walker BA, Halpern BL, Kuzma JW, McKussick VA. Life expectancy and causes of death in the Marfan syndrome. N Engl F Med 1972;286:804-8.

3 Marsalese DL, Moodie DS, Vacante M, Lytle BW, Gill CC, Sterta R. Marfan's syndrome: natural history and long-term follow-up of cardiovascular involvement. $7 \mathrm{Am}$ Coll Cardiol 1989;14:422-8.

4 Roman MJ, Rosen SE, Kramer-Fox R, Devereux RB. Prognostic significance of the pattern of aortic root dilation Prognostic significance of the pattern of aortic root dilation
in the Marfan syndrome. $f \mathrm{Am}$ Coll Cardiol 1993;22: in the $1470-6$.

5 Hwa J, Richards JG, Huang M, McKay D, Pressley L, Hughes CF, et al. The natural history of aortic dilation in Marfan syndrome. Med f Aust 1993;158:558-62.

6 Shores J, Berger KR, Murphy EA, Pyeritz RE. Progression of aortic root dilation and the benefit of long-term $\beta$ adrenergic blockade in Marfan's syndrome. $N$ Engl $₹$ Med 1994;330:1335-41.

7 Roman MJ, Devereux RB, Kramer-Fox R, O'Loughlin J. Two-dimensional echocardiographic aortic root dimensions in normal children and adults. Am $\mathcal{F}$ Cardiol 1989; 64:507-12.
8 Quinones MA, Young JB, Waggoner AD, Ostojic MC, Ribeiro LG, Miller R. Assessment of pulsed Doppler echocardiography on detection and quantification of aor

tic and mitral regurgitation. Br Heart $1980 ; 44: 612-20$.

Wine RA, Stathogiannis E, Newell JB, Harrigan P, Weyman AG. Reconsideration of echocardiographic standards for mitral valve prolapse: lack of association between leaflet displacement isolated to the apical 4chamber view and independent echocardiographic evi-

10 Helmcke F, Nanda NC, Hsiung MC, Soto B, Adey CK, Goyal RG, et al. Color Doppler assessment of mitral regurgitation with orthogonal planes. Circulation 1987;

11 Gott VL, Pyeritz RE, Cameron DE, Greene PS, McKusick VA. Composite graft repair of Marfan aneurysm of the ascending aorta: results in 100 patients. Ann Thorac Surg 1991;52:38-45.

12 Svensson LG, Crawford ES, Coselli JS, Safi MJ, Mess KR. Impact on cardiovascular operation on survival in the Marfan patient. Circulation 1989;80(suppl I):I233-42.

13 Smith JA, Fann JI, Miller DC, Moore KA, DeAnda A Jr Mitchell RS, et al. Surgical management of aortic dissection in patients with the Marfan syndrome. Circulation 1994;90(part 2):II235-42.

14 Treasure T. Elective replacement of the aortic root on Marfan's syndrome. Br Heart f 1993;69:101-3.

15 Pyeritz RE. Predictors of dissection of the ascending aorta in Marfan syndrome [abstract]. Circulation 1991:84 (suppl II):II351.

16 Simpson IA, de Belder MA, Treasure T, Camm AJ, Pumphrey $\mathrm{CW}$. Cardiovascular manifestations of Marfan's syndrome: improved evaluation by transesophageal echocardiography. Br Heart f 1993;69:104-8.

17 Murgatroyd F, Child A, Polonieux J, Treasure T, Pumphrey CW. Does routine echocardiographic assessment of the aortic root diameter help predict the risk of dissection in the Marfan syndrome? [abstract] Eur Heart $\mathcal{f}$ dissection in the Marf
$1991 ; 12$ (suppl):410.

1991;12(suppl):410.
18 Bentall HM, DeBono A. A technique for complete replacement of the ascending aorta. Thorax 1968;23:338-9.

19 Silverman DI, Grey J, Roman MJ, et al. A family history of severe cardiovascular disease in the Marfan syndrome is associated with increased aortic diameter and decreased survival [abstract]. Circulation 1994;90(suppl I):I385.

20 Pereira L, Levran O, Ramirez F, Lynch JR, Sykes B, Pyeritz RE, et al. A molecular approach to the stratification of cardiovascular risk in families with Marfan's syndrome. N Engl f Med 1994;331:148-53. 